\title{
Reversion free high-temperature vulcanization of cis-polybutadiene rubber with the accelerated-sulfur system
}

\author{
S. Gopi Sathi ${ }^{*}$, R. Stoček, O. Kratina \\ Centre of Polymer Systems, Tomas Bata University in Zlín, Třida Tomáše Bati 5678, 76001 Zlín, Czech Republic
}

Received 22 November 2019; accepted in revised form 23 January 2020

\begin{abstract}
The vulcanization of high diene elastomers with conventional or semi-efficient vulcanization systems exhibit reversion at a higher temperature due to the breakage of the polysulfidic crosslinks established in the vulcanized network. As a result, the vulcanizate show inferior mechanical and thermal stability at elevated temperature. In this contest, the anti-reversion ability of Maleide $\mathrm{F}$ ( $75 \% N, N^{\prime}$-meta phenylene dimaleimide and a $25 \%$ blending agent: MF) was evaluated on the vulcanization behavior of cis-polybutadiene rubber (BR) with a conventional accelerated sulfur system. The anti-reversion ability of MF was also compared with Perkalink 900 (1,3-bis (citraconimidomethyl) benzene: PL). Based on the vulcanization studies using a moving die rheometer, it has been realized that MF forms carbon-carbon based bismaleimide crosslinks at the beginning of the vulcanization via Alder-Ene reaction. As a result, MF-filled systems exhibit a remarkable reversion resistance and a plateau type cure behavior even at $180^{\circ} \mathrm{C}$ for a period of $1 \mathrm{hr}$. On the other hand, PL shows its anti-reversion activity via Diels-Alder reaction after a short reversion. Moreover, the PL filled system exhibits a marching-modulus cure behavior at a higher vulcanization temperature. Therefore, PL cannot be considered as a promising candidate for the hightemperature vulcanization of BR with accelerated sulfur.
\end{abstract}

Keywords: rubber, vulcanization, bismaleimide, reversion, Diels-Alder reaction

\section{Introduction}

It has been well-documented in the literature that the accelerated-sulfur systems are classified as conventional vulcanization (CV), efficient vulcanization (EV), and semi-efficient vulcanization (SEV) based on their accelerator to sulfur ratio. Generally, the accelerator/sulfur ratio for a $\mathrm{CV}$ system is in the range of 0.1 to 0.6 . For SEV, it is about 0.7 to 2.5 and for the EV system, it will be greater than 2.5 [1-4]. It has also been reported that the vulcanizate of a $\mathrm{CV}$ cured network comprises $95 \%$ poly and disulfidic crosslinks and 5\% mono-sulfidic crosslinks. For SEV, $50 \%$ of the cross-links will be poly-and di-sulfidic and the rest will be mono-sulfidic. However, the amount of mono-sulfidic cross-links will be around $80 \%$ if the rubber is cured with an EV system [1]. Because of the poor thermal stability of the polysulfidic crosslinks, the high diene rubbers vulcanized with the CV or SEV systems exhibit reversion when exposed to a temperature-time treatment. The breakage of the polysulfidic crosslinks formed during the initial stages of the vulcanization is considered as one of the major reasons behind the reversion process. A gradual reduction in the rheometric torque from its maximum value during vulcanization is one of the direct evidence of reversion. Owing to reversion, the $\mathrm{CV} / \mathrm{SEV}$ vulcanized diene rubbers show poor physical properties like cross-link density and compression set at elevated temperatures [5-7]. Therefore, the vulcanization of diene elastomers with $\mathrm{CV}$ or SEV is limited to a lower curing temperature preferably at 140 to $150^{\circ} \mathrm{C}$. This low-temperature vulcanization for thick rubber products like tire may take a longer time to reach a full state of cure which leads 
to lower production capacity. Therefore, the development of a reversion free accelerated-sulfur vulcanizing system for the diene rubbers is critical.

Various types of chemicals such as hexamethylene bisthiosulphate disodium salt (Duralink ${ }^{\circledR} \mathrm{HTS}$ ), bis (triethoxysilylpropyl)-tetrasulphide (TESPT), thiuram accelerators, dithiophosphate accelerators (Vocol ZBPD) have been employed to outwit the reversion during the vulcanization of truck tire tread compounds based on natural rubber (NR) with a CV system [8]. Furthermore, Blok et al. [9] explored the use of certain multifunctional acrylates as an anti-reversion agent in NR with a SEV system. Kenneth [10] reported that chemicals such as Struktol ${ }^{\circledR}$ ZB47 and Struktol ${ }^{\circledR}$ SA1341(-a formulated zinc soap produced by the Struktol Company of America, LLC) can show a considerable anti-reversion property in an NR compound with a SEV system in addition to its role as a processing aid. The bismaleimide based compound like 1,3-bis(citraconimidomethyl)benzene (Perkalink 900) is another important class of chemicals which can show an excellent anti-reversion property in diene rubbers. Many researchers have tested its efficiency as an anti-reversion agent in various NR based rubber compounds [11-14]. Recently, the author has reported the use of a 4,4'-bis(maleimido)diphenylmethane as an anti-reversion agent for the vulcanization of NR with a CV system [15].

In the present work, the anti-reversion efficiency of two different bismaleimide based chemicals such as Perkalink 900 (PL) and Maleide F (MF) was investigated on the vulcanization behavior of an unfilled cis-polybutadiene rubber with an accelerated sulfur system. The influence of these chemicals on the vulcanizate properties like crosslink density, shore hardness and compression set properties was also evaluated. To the best of our knowledge, no reports are available in the literature regarding the anti-reversion ability of MF on polybutadiene rubber.

\section{Experimental}

\subsection{Materials}

High cis-polybutadiene rubber, SYNTECA ${ }^{\circledR} 44$ (cis1,4 content: $97 \%$, Mooney viscosity $\operatorname{ML}(1+4)$ at $100{ }^{\circ} \mathrm{C}$ : 39$)$ was procured from Synthos PBR s.r.o., Czech Republic. Maleide F (MF) is a combination of $75 \% N, N^{\prime}$-meta phenylene dimaleimide and $25 \%$ blending agent was procured from Krata Pigment, Tambov, Mentazhnikov, Russia and Perkalink 900 (PL) is chemically 1,3-bis(citraconimidomethyl) a)<smiles>O=C1C=CC(=O)N1c1cccc(N2C(=O)C=CC2=O)c1</smiles>

b)<smiles>CC1=CC(=O)N(Cc2cccc(CN3C(=O)C=C(C)C3=O)c2)C1=O</smiles>

Figure 1. Chemical structures of (a) Maleide F and (b) Perkalink 900.

benzene was procured from Lanxess Deutschland $\mathrm{GmbH}$, Leverkusen, Germany. The chemical structures of MF and PL are shown in Figure 1. Other ingredients such as sulfur, $n$-cyclohexyl-2-benzothiazole sulfenamide (CBS), stearic acid and zinc oxide $(\mathrm{ZnO})$ were purchased from Sigma-Aldrich, Czech Republic.

\subsection{Preparation of rubber compounds}

The formulations of the compounds with designations are displayed in Table 1. All the compounds were prepared using an internal mixer (Brabender Plastograph, GmbH \& Co. KG, Germany) having a chamber volume of $50 \mathrm{~cm}^{3}$. A fill-factor of 0.8 was taken for the efficient mixing of the ingredients. The neat BR has masticated at $60^{\circ} \mathrm{C}$ under $50 \mathrm{rpm}$ for $1 \mathrm{~min}$. To this, the $\mathrm{ZnO}$, stearic acid, and bismaleimides were added and continued the mixing under the same rotor speed and temperature for another $2 \mathrm{~min}$. The curatives (sulfur and accelerator) were then added and mixed for 1 more min. After the mixing, the compound was discharged and homogenized using a two-roll mill. It is then molded into a $1 \mathrm{~mm}$ sheet by applying a constant force of $200 \mathrm{~N}$ using a compression molding heat press LaBEcon

Table 1. Formulation of the mixes (unit: phr).

\begin{tabular}{|l|c|c|c|}
\hline Ingredients & BR-S $^{\mathbf{a}}$ & $\mathbf{B R - S}^{\mathbf{b}} \mathbf{M F}_{\mathbf{1}}$ & $\mathbf{B R}^{\mathbf{c}} \mathbf{P}_{\mathbf{1}}$ \\
\hline $\mathrm{BR}$ & 100 & 100 & 100 \\
\hline $\mathrm{ZnO}$ & 4 & 4 & 4 \\
\hline Stearic acid & 2 & 2 & 2 \\
\hline Sulfur & 2 & 2 & 2 \\
\hline $\mathrm{CBS}$ & 0.6 & 0.6 & 0.6 \\
\hline Maleide F & - & 1 & - \\
\hline Perkalink 900 & - & - & 1 \\
\hline
\end{tabular}

${ }^{a}$ Sulfur,

${ }^{b}$ Maleide F,

'Perkalink 900 
300 (Fontijne Presses, The Netherland) for the respective cure time obtained from the rheometer cure data for the selected molding temperature.

\subsection{Characterization}

\subsubsection{Cure characteristics}

Maximum torque: $S_{\max }^{\prime}$, minimum torque: $S_{\min }^{\prime}$, the difference between maximum and minimum torque: $\Delta S^{\prime}$, scorch time: $T_{\mathrm{S} 2}$, optimum cure time: $T_{90}$ (the time required for the torque to reach $90 \%$ of the maximum torque) of the rubber compounds were determined from the cure curves from a moving die rheometer (MDR-3000, Mon-Tech, Germany) at various vulcanization temperatures as per ASTM D 5289. The cure rate index $(C R I)$, a measure of the rate of curing, was calculated using the Equation (1):

$C R I=\frac{100}{T_{90}-T_{\mathrm{S} 2}}$

\subsubsection{Crosslink density measurements}

Samples with a diameter of $20 \mathrm{~mm}$ and a thickness of $1 \mathrm{~mm}$ were swelled in toluene at room temperature until it reached an equilibrium state of swelling. The swelled samples were then taken out and wiped off the adhered solvent from the surface using a filter paper and immediately recorded the weights $\left(W_{\mathrm{s}}\right)$. Afterward, the swollen samples were dried at room temperature for $24 \mathrm{hrs}$ and ensured that the absorbed toluene has completely expelled out. Then, we measured the dried weight of the samples $\left(W_{\mathrm{d}}\right)$. From the values of $W_{\mathrm{s}}$ and $W_{\mathrm{d}}$, the cross-link density n of the samples was calculated using the Flory-Rehner equation given in Equation (2) [16-18]:

$n=\frac{-\left[\ln \left(1-V_{\mathrm{r}}\right)+V_{\mathrm{r}}+\chi V_{\mathrm{r}}^{2}\right]}{V_{\mathrm{s}}\left[V_{\mathrm{r}}^{1 / 3}-\frac{V_{\mathrm{r}}}{2}\right]}$

where $V_{\mathrm{r}}$ is the volume fraction of rubber in the equilibrium swollen sample, $V_{\mathrm{s}}$ is the molar volume of the solvent $(106.3 \mathrm{ml} / \mathrm{mol}$ for toluene at room temperature) and $\chi(0.387)$ is the coefficient of the interaction between the rubber and the solvent. Here, $V_{\mathrm{r}}$ was calculated using Equation (3) and $\chi$ was determined from Equation (4) [19, 20]:

$$
\begin{aligned}
& V_{\mathrm{r}}=\frac{W_{\mathrm{d}}}{W_{\mathrm{d}}+\left(W_{\mathrm{s}}-W_{\mathrm{d}}\right) \frac{\rho_{\text {rubber }}}{\rho_{\text {solvent }}}} \\
& \chi=\beta+\frac{V_{\mathrm{s}}}{R T}\left(\delta_{\mathrm{s}}-\delta_{\mathrm{r}}\right)^{2}
\end{aligned}
$$

where $W_{\mathrm{s}}$ is the weight of the equilibrium swelled rubber, and $W_{\mathrm{d}}$ is the dry weight of the swelled rubber. $\beta$ is the lattice constant (typically 0.34 ) [21], $\rho$ is the density, $R$ is the molar gas constant, and $T$ is the absolute temperature. The solubility parameters of the rubber $\left(\delta_{\mathrm{r}}\right)$ and the solvent $\left(\delta_{\mathrm{s}}\right)$ for BR and toluene were taken as 17.15 and $18.2 \mathrm{MPa}^{1 / 2}$ respectively [21].

\subsubsection{Hardness testing}

Cured samples having smooth surfaces with $12.5 \mathrm{~mm}$ thickness and $29 \mathrm{~mm}$ diameter were used to measure the indentation hardness using a Shore-A hardness tester (Bareiss Durometer, Germany) as per ASTM D 2240. Indentations were made on different areas of the samples by applying constant pressure for 15 seconds. 6 readings were taken from different areas of the sample and reported the average value.

\subsubsection{Compression set}

The compression set $(C S)$ was measured as per ASTM D 395 using the set produced by Coesfeld $\mathrm{GmbH}$, Germany. Cylindrical samples having $12.5 \mathrm{~mm}$ thickness and $29 \mathrm{~mm}$ diameter were subjected to a $25 \%$ compression. The compressed samples then kept in an air-oven at $100^{\circ} \mathrm{C}$ for $22 \mathrm{hrs}$. After the specified testing time, the samples were taken out and allowed to cool for 30 minutes at room temperature and measured the thickness. The $C S$ was calculated using Equation (5):

$\operatorname{CS}[\%]=\frac{t_{0}-t_{\mathrm{f}}}{t_{0}-t_{\mathrm{s}}} \cdot 100$

where $t_{0}$ and $t_{\mathrm{f}}$ are the original and final thickness of the specimen, and $t_{\mathrm{s}}$ is the thickness of the spacer used.

\subsubsection{Thermogravimetric analysis}

Thermogravimetric analyses (TGA) were conducted to evaluate the thermal stability or the thermal degradation behavior of the vulcanized rubber compounds using a TA instrument (Q500, USA). Cured samples were heated from room temperature to $600^{\circ} \mathrm{C}$ at a heating rate of $10^{\circ} \mathrm{C} / \mathrm{min}$ under nitrogen atmosphere.

\section{Results and discussion}

\subsection{Vulcanization behavior of BR-S}

Represented in Figure 2 is the vulcanization behavior of BR with a conventional accelerated sulfur system (BR-S) at three different vulcanization temperatures 


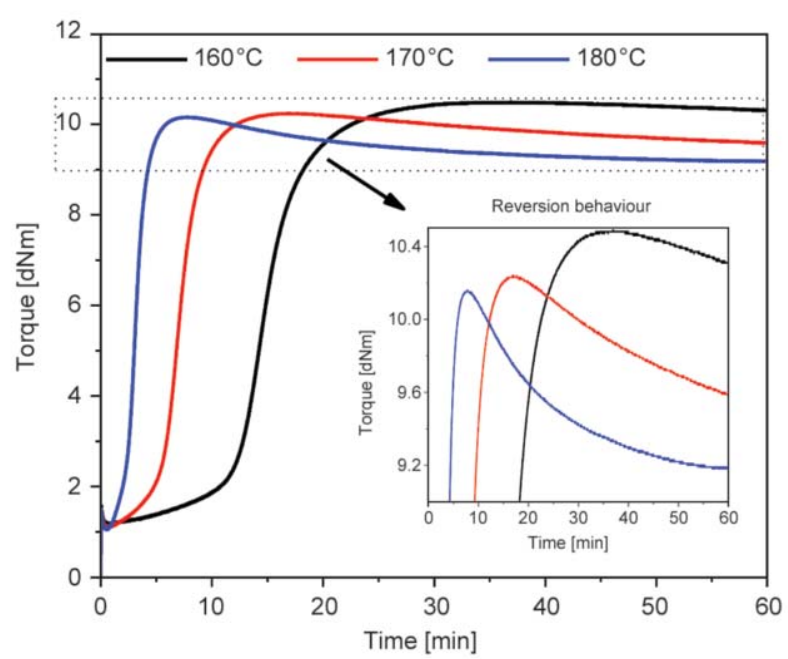

Figure 2. Vulcanization behaviour of BR-S under different temperatures for $60 \mathrm{~min}$.

for $60 \mathrm{~min}$. The detailed cure characteristics are displayed in Table 2. As expected, the speed of vulcanization increased with the increase in temperature, which is evident from the significant increase in the cure rate index. For instance, the $T_{\mathrm{S} 2}$ value at $160^{\circ} \mathrm{C}$ was $12.9 \mathrm{~min}$ which has been reduced to $2.5 \mathrm{~min}$ by raising the vulcanization temperature to $180^{\circ} \mathrm{C}$. It is important to note that as the vulcanization temperature increased, the torque was found decreased soon after the maximum torque due to reversion. One of the widely accepted reasons for the reversion during the accelerated sulfur vulcanization is the breakage of the polysulfidic linkages which were formed at the initial stages of the vulcanization process. Since the susceptibility of the breakage of a polysulfidic crosslink is more likely at a higher temperature, the severity of reversion was also higher at a higher vulcanization temperature $[4,5]$. As a result, the onset of reversion was shifted from $39.3 \mathrm{~min}$ at $160^{\circ} \mathrm{C}$ to $8.2 \mathrm{~min}$ as the vulcanization temperature rose to $180^{\circ} \mathrm{C}$. The intensity of reversion was calculated using the following Equation (6) [11, 14]:
Table 3. Percentage reversion in BR-S at different time intervals from the maximum torque under different temperatures.

\begin{tabular}{|c|c|c|c|}
\hline \multirow{2}{*}{$\begin{array}{c}\text { Tempera- } \\
\text { ture }\end{array}$} & \multicolumn{3}{|c|}{$\begin{array}{c}\text { Reversion } \\
{[\%]}\end{array}$} \\
\cline { 2 - 4 }$\left[{ }^{\circ} \mathbf{C}\right]$ & $\begin{array}{c}\text { After 15 min } \\
\left(\boldsymbol{S}_{\text {max }}^{\prime}+\mathbf{1 5} \text { min }\right)\end{array}$ & $\begin{array}{c}\text { After 30 min } \\
\left(\boldsymbol{S}_{\text {max }}^{\prime}+\mathbf{3 0} \text { min }\right)\end{array}$ & $\begin{array}{c}\text { After 45 min } \\
\left(\boldsymbol{S}_{\text {max }}^{\prime}+\mathbf{4 5} \text { min }\right)\end{array}$ \\
\hline 160 & 0.5 & 2.1 & - \\
\hline 170 & 2.9 & 5.9 & 7.5 \\
\hline 180 & 5.5 & 8.2 & 9.0 \\
\hline
\end{tabular}

Reversion $[\%]=\frac{S_{\text {max }}^{\prime}-S_{\text {max }+\mathrm{t}}^{\prime}}{S_{\text {max }}^{\prime}} \cdot 100$

where $S_{\max }^{\prime}$ is the maximum torque and $S_{\max +\mathrm{t}}^{\prime}$ is the torque at a time $t$ after $S_{\text {max }}^{\prime}$.

Represented in Table 3 is the percentage reversion that is observed during the vulcanization of BR-S at different time intervals under different vulcanization temperatures. It is clear that as the time and temperature of vulcanization increases, the percentage of reversion also increases.

\subsection{Vulcanization behavior of BR-S in the presence of bismaleimides}

To prevent the reversion that is observed during the vulcanization of BR-S, two types of bismaleimides such as PL and MF, were applied as anti-reversion chemicals. Depicted in Figure 3 are the representative cure curves of BR-S in the presence of $1 \mathrm{phr} P \mathrm{PL}$ $\left(\mathrm{BR}-\mathrm{SPL}_{1}\right)$ and $1 \mathrm{phr} \mathrm{MF}\left(\mathrm{BR}-\mathrm{SMF}_{1}\right)$ at 160 and $180^{\circ} \mathrm{C}$ for $60 \mathrm{~min}$. Their cure characteristics obtained for all the vulcanization temperatures are also displayed in Table 2. The cure patterns of BR-S and BR-SPL $L_{1}$ were similar during the initial stage of the reaction. As a result, their $T_{\mathrm{S} 2}$ values were also been similar at all the vulcanization temperatures. From the inset of Figure $3 b$, it is clear that BR-SPL $L_{1}$ exhibits a marching modulus cure behavior just after a

Table 2. Cure characteristics of the mixes.

\begin{tabular}{|l|c|c|c|c|c|c|c|}
\hline Compounds & $\begin{array}{c}\text { Temperature } \\
{\left[{ }^{\circ} \mathbf{C}\right]}\end{array}$ & $\boldsymbol{S}_{\text {min }}^{\prime}$ & $\boldsymbol{S}^{\prime}{ }_{\text {max }}$ & $\boldsymbol{\Delta S}^{\prime}$ & $\begin{array}{c}\boldsymbol{T}_{\mathbf{S} 2} \\
{[\mathbf{m i n}]}\end{array}$ & $\begin{array}{c}\boldsymbol{T}_{\mathbf{9 0}} \\
{[\mathbf{m i n}]}\end{array}$ & $\begin{array}{c}\text { Cure rate index } \\
{\left[\mathbf{m i n}^{-1} \mathbf{]}\right.}\end{array}$ \\
\hline \multirow{3}{*}{ BR-S } & 160 & 1.2 & 10.5 & 9.3 & 13.0 & 20.0 & 14.3 \\
\cline { 2 - 8 } & 170 & 1.1 & 10.2 & 9.1 & 6.0 & 9.7 & 27.0 \\
\cline { 2 - 8 } & 180 & 1.0 & 10.2 & 9.2 & 2.5 & 4.4 & 52.6 \\
\hline \multirow{3}{*}{ BR-SPL $_{1}$} & 160 & 1.2 & 10.5 & 9.3 & 13.3 & 20.8 & 13.3 \\
\cline { 2 - 8 } & 170 & 1.1 & 10.7 & 9.6 & 6.1 & 12.0 & 16.9 \\
\hline \multirow{3}{*}{ BR-SMF $_{1}$} & 180 & 1.0 & 11.3 & 10.2 & 2.4 & 22.7 & 4.9 \\
\cline { 2 - 8 } & 160 & 1.2 & 10.9 & 9.7 & 14.5 & 38.2 & 4.2 \\
\cline { 2 - 8 } & 170 & 1.1 & 11.2 & 10.1 & 6.5 & 20.2 & 7.3 \\
\hline
\end{tabular}



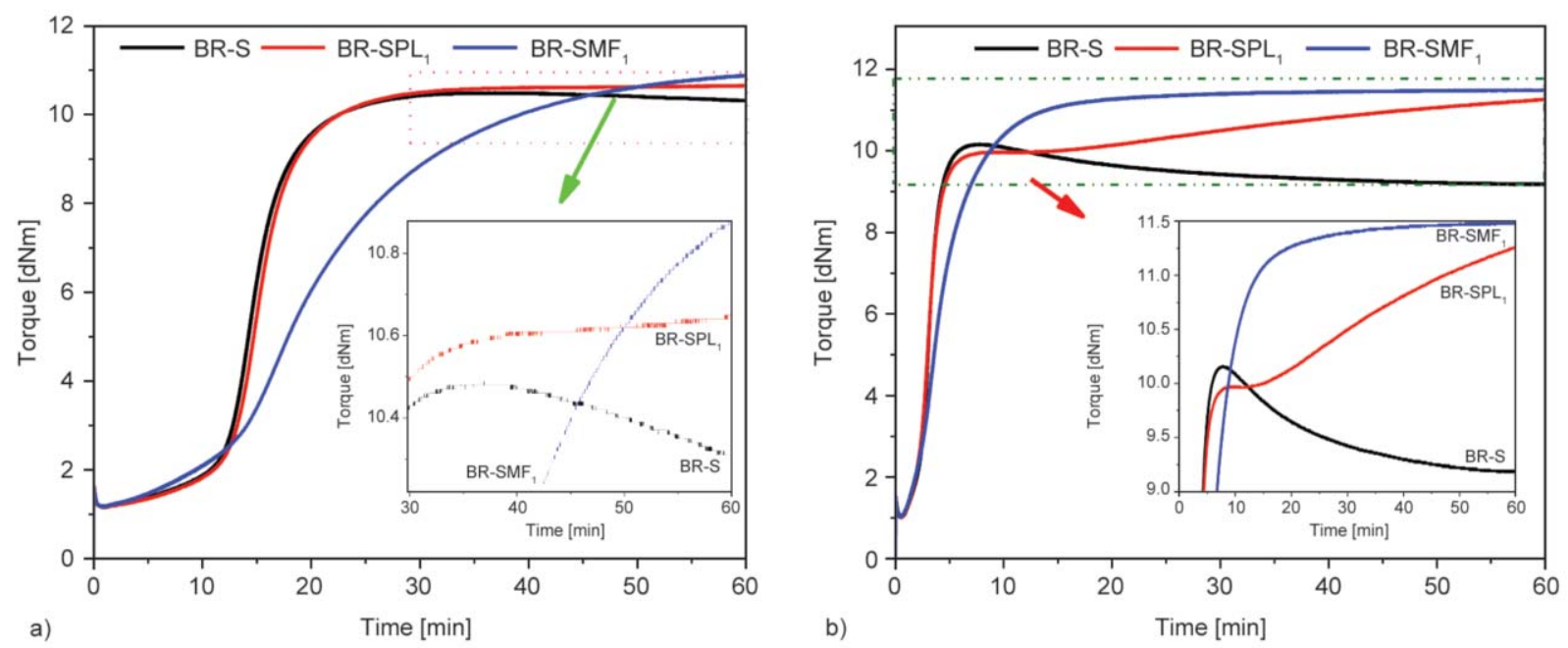

Figure 3. Cure curves of BR-S, BR-SPL 1 and $\mathrm{BR}-\mathrm{SMF}_{1}$ (a) at $160^{\circ} \mathrm{C}$ and (b) at $180^{\circ} \mathrm{C}$ for $60 \mathrm{~min}$.

short reversion. This means that at a higher vulcanization temperature, the PL can act as an anti-reversion agent only after a small reversion has already happened in the system. Since the curing behavior of BR-SPL $\mathrm{S}_{1}$ exhibits a distinct marching modulus just after the onset of reversion particularly at $180^{\circ} \mathrm{C}$, the time to optimum cure shows a higher value when compared to BR-S. Based on the Fourier transform Raman spectroscopic investigations, it has been reported that the sulfur vulcanized network of diene rubbers comprises isomerized double bonds, conjugated unsaturated bond and cyclic sulfide units in addition to the mono, di and poly sulfidic crosslinks [1, 22-24]. Therefore, it is reasonable to assume that when the polysulfidic crosslink breaks during reversion, the conjugated diene units in the vulcanized network may be exposed to react if any dienophiles are present in the system. Hence, the possibility of Diels-Alder reaction can be considered high to explain the anti-reversion property of BR-S with PL. As per this reaction mechanism, as soon as the conjugated diene units been exposed at the point of reversion, the maleimide moieties of PL will react with it and produce a cyclic adduct type crosslinks as depicted in Figure 4. From Figure 3a, it is also clear that BR-SPL $L_{1}$ does not show a significant marching modulus curing behavior at $160^{\circ} \mathrm{C}$ even after the onset of reversion till the end of 60 min curing. This may be due to the less breakage of the polysulfidic crosslinks and less availability of the conjugated unsaturation for the Diels-Alder reaction to take place at $160^{\circ} \mathrm{C}$. However, as the vulcanization temperature increased to $180^{\circ} \mathrm{C}$, more polysulfidic cross-links are getting broken and hence the conjugated unsaturation becomes more exposed to react with the maleimide moieties of PL via Diels-Alder reaction. As a result, the vulcanization curve of BR-SPL shows a distinct marching modulus cure behavior

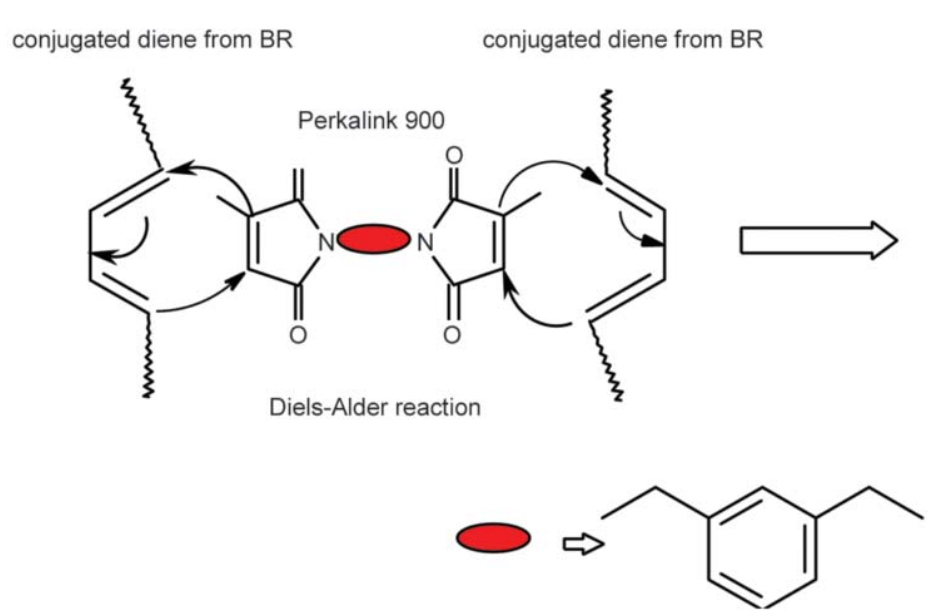

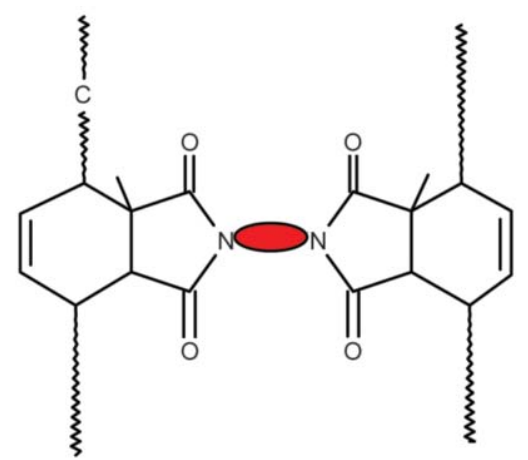

Cross-linked BR via Perkalink 900

Figure 4. Schematic representation of the cross-linking reaction between the in-situ formed conjugated diene from BR-S and Perkalink via Diels-Alder reaction. 
just after 10 minutes of curing at $180^{\circ} \mathrm{C}$. Based on these experimental observations, the vulcanized network of BR-S and BRS-PL ${ }_{1}$ before and after reversion can be pictorially depicted as shown in Figure $5 \mathrm{a}$ and $5 \mathrm{~b}$ respectively. On the other hand, the speed of the vulcanization of BR-S was considerably reduced particularly at $160^{\circ} \mathrm{C}$ with the addition of $1 \mathrm{phr}$ MF. As a result, the cure curve of BR-SMF exhibits a marching modulus behavior right from the beginning of the reaction and therefore never attained a cure plateau till the end of the reaction at $160{ }^{\circ} \mathrm{C}$. However, the cure curve shows a plateau region after 40 minutes of curing at $170^{\circ} \mathrm{C}$ and after 25 minutes of curing at $180^{\circ} \mathrm{C}$. Here it is worth noting that the cure curve of $\mathrm{BR}-\mathrm{SMF}_{1}$ does not exhibit any sign of reversion till the end of the vulcanization reaction even at a $180^{\circ} \mathrm{C}$. This indicates that the antireversion ability of MF is superior to PL 900 during the vulcanization of polybutadiene rubber with accelerated sulfur.

\subsection{Proposed reaction mechanism for the superior anti-reversion property of MF}

It has been noticed that the addition of MF significantly affected the speed of the curing reaction in $\mathrm{BRS}$, particularly at $160^{\circ} \mathrm{C}$. This means that MF can interfere with the normal sulfur vulcanization process at the beginning of the reaction. The Alder-ene reaction between the polybutadiene and the maleic moieties of MF can be considered as one of the probable reasons for this $[25,26]$. As per this reaction mechanism, the ene group present in MF abstract an allyl hydrogen atom from the polybutadiene and forms bismaleimide crosslinks as represented in Figure 6. The possibility of this Alder-ene reaction between BR and MF may lead to connecting the polybutadiene chains via few numbers of bismaleimide crosslinks before it is getting connected via sulfur crosslinks. If so, the vulcanized network of BR-SMF 1 comprises a mixture of mono, di- and polysulfidic sulfur crosslinks along with the bismaleimide crosslinks as

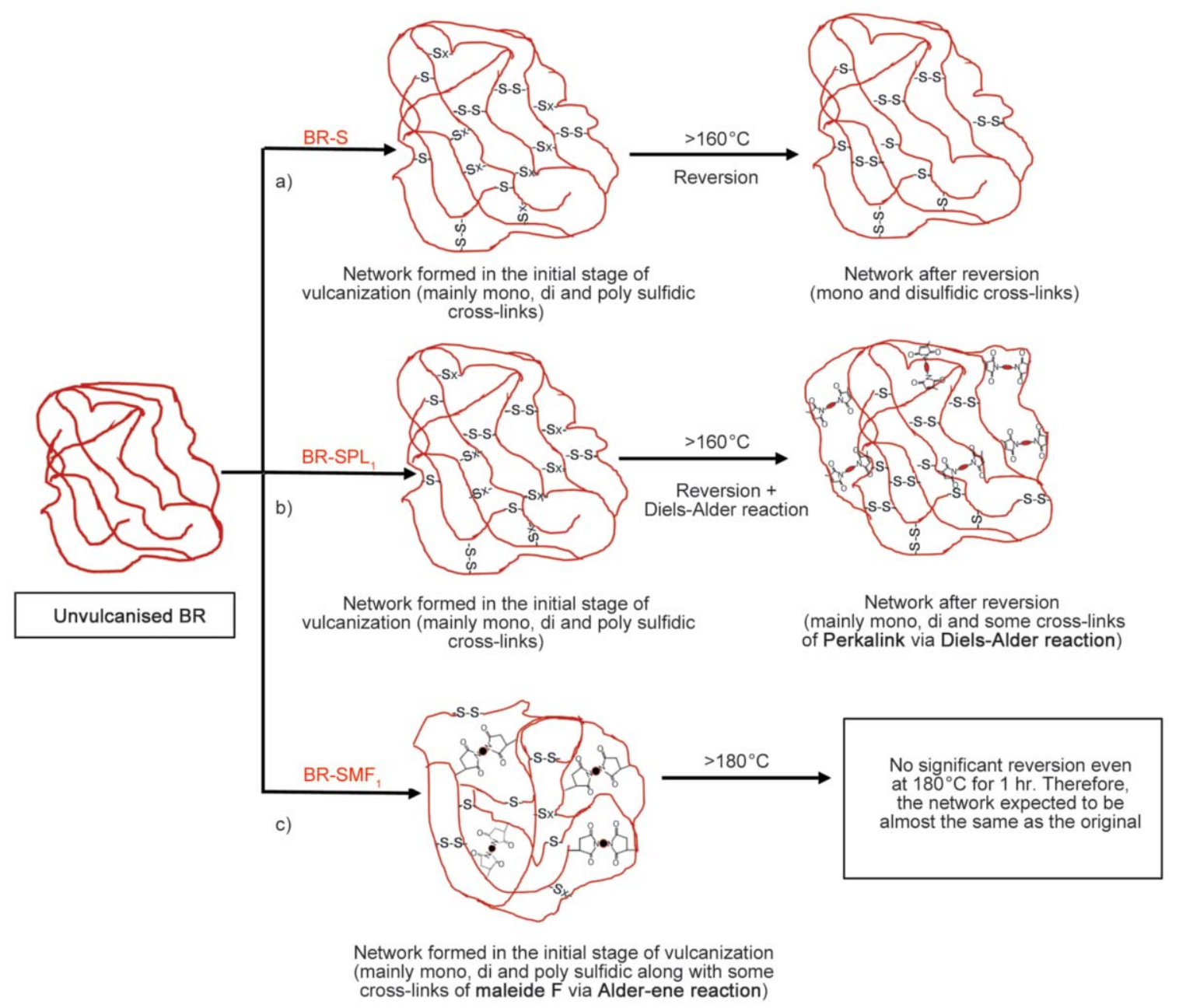

Figure 5. Surmised network structures of (a) BR-S, (b) BR-SPL 1 and (c) BR-SMF 1 before and after the reversion. 

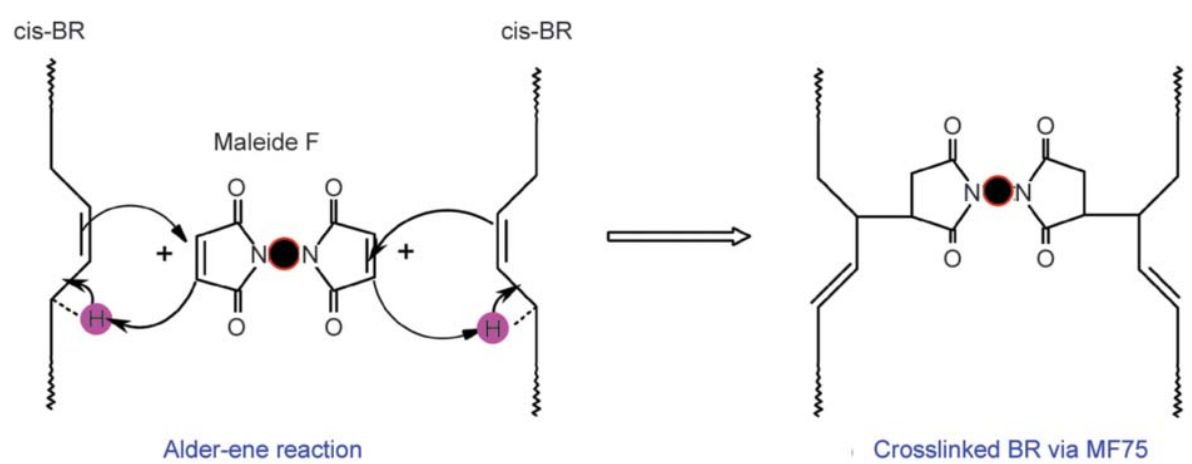

Allylic hydrogen

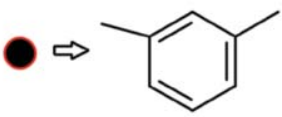

Figure 6. Schematic representation of the cross-linking reaction between polybutadiene and Maleide F via Alder-ene reaction.

depicted in Figure 5c. Because of the aromatic ring structure, the thermal stability of the vulcanizate consist of bismaleimide crosslinks is better than the vulcanizate formed with only a mixture of mono, di and polysulfidic crosslinks as in BR-S. This thermally stable bismaleimide crosslinks which are generated during the initial stages of the crosslinking reaction is responsible for the superior anti-reversion property of MF. However, owing to the bulky nature of the initially formed bismaleimide crosslinks, it may be hindered or delay in the formation of sulfur crosslinks. This may be one of the reasons for the higher $T_{\mathrm{S} 2}$ and $T_{90}$ values observed in the vulcanization of $\mathrm{BR}-\mathrm{SMF}_{1}$ particularly at $160^{\circ} \mathrm{C}$. On the other hand, because of the electron-donating methyl groups attached to the maleimide moieties, the possibility of Alder-ene reaction between polybutadiene and PL seems somewhat difficult or may take place at a very slow rate [27]. As a result, PL does not interrupt the sulfur vulcanization process at the initial stages of the vulcanization reaction and hence does not alter the speed of the reaction. Since no maleimide crosslinks are being produced in the initial stage of the vulcanization of BR-SPL ${ }_{1}$, its vulcanized network after the initial stage of reaction (before the onset of reversion) may consist of only mono, di and polysulfidic crosslinks as shown in Figure 5b. However, after reversion, because of the possibility of DielsAlder reaction as mentioned earlier, its vulcanized network comprises a mixture of sulfur (mainly mono and di sulfidic) and bismaleimide crosslinks as shown in the figure.

\subsection{Evidences supporting the possibilities of Alder-ene reaction between $B R$ and MF}

To support the proposed Alder-ene reaction described in Figure 6, we have conducted the curing reactions of polybutadiene with bismaleimides alone. Represented in Figure 7 are the MDR cure curves and the corresponding rate of the curing reactions of polybutadiene with $1 \mathrm{phr}$ MF $\left(\mathrm{BR}-\mathrm{MF}_{1}\right)$ and $1 \mathrm{phr} \mathrm{PL}$ (BR-PL ${ }_{1}$ ) at 160 and $180^{\circ} \mathrm{C}$ for a period of $60 \mathrm{~min}$. For a comparative purpose, the cure curve of BR-S was also incorporated in the above figures. The cure curves of BR with MF was relatively fast during the initial stage of the reaction compared to BR-S. For instance, at $160^{\circ} \mathrm{C}$, the vulcanization curve of BR$\mathrm{MF}_{1}$ took only $2.3 \mathrm{~min}$ to raise 0.5 units of torque from the minimum value. However, BR-S took around $8.7 \mathrm{~min}$ to raise the same amount of torque from its minimum torque value. From the inset of Figure 7a, it can be seen that after an initial rapid reaction, the cure curve of BR-MF ${ }_{1}$ becomes very slow and exhibits a marching modulus cure behavior. However, the reaction between BR and PL was very feeble at both 160 and $180^{\circ} \mathrm{C}$. Therefore, the cure curve of BR-PL ${ }_{1}$ does not show any significant vulcanization torque with time. This experimental evidences strongly confirms that the only possible reaction in $\mathrm{BR}+\mathrm{MF}$ is the Alder-ene reaction as depicted in Figure 6. Because of the bulky nature of the bismaleimide crosslinks which are initially been generated due to Alder-ene reaction may prohibit or slow down the formation of further bismaleimide crosslinks. This is probably one of the reasons for the low 

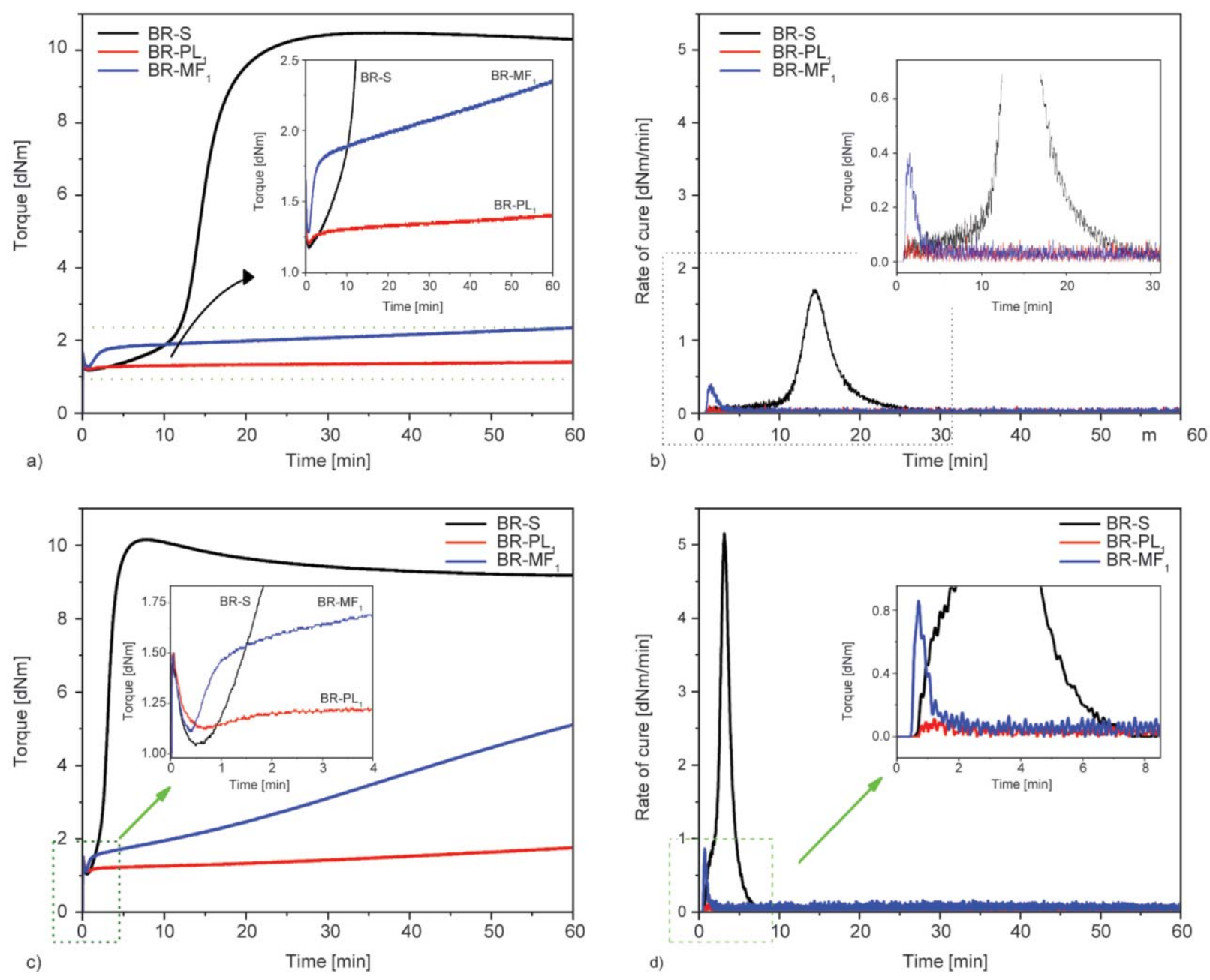

Figure 7. The MDR cure curves and the corresponding rate of the curing reactions of BR-S, BR-MF 1 and $B R-\mathrm{PL}_{1}(\mathrm{a}, \mathrm{b})$ at $160^{\circ} \mathrm{C}$ and $(\mathrm{c}, \mathrm{d})$ at $180^{\circ} \mathrm{C}$ for a period of $60 \mathrm{~min}$.

rate of vulcanization and a marching modulus cure behavior in $\mathrm{BR}-\mathrm{MF}_{1}$ after an initial rapid reaction. On the other hand, because of the electron-donating methyl substituents on the maleimide moieties of $\mathrm{PL}$, the Alder-ene reaction between BR and PL is extremely slow or almost negligible even at $180^{\circ} \mathrm{C}$. Therefore, the vulcanization torque is very poor which can be visualized through the Figures 7 .

\subsection{Vulcanization kinetics}

Represented in Figure 8 are the cure rate curves of BR-S, BR-SPL ${ }_{1}$, and BR-SMF ${ }_{1}$ at three different vulcanization temperatures $\left(160,170\right.$ and $\left.180^{\circ} \mathrm{C}\right)$ obtained from the MDR analysis. The time required to reach the maximum rate of reaction for BR-S and

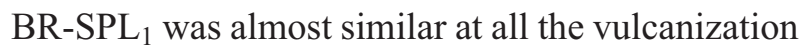

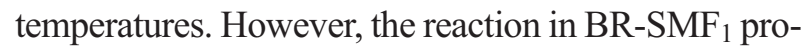
ceeds with a lower speed and takes a long time to attains the maximum rate at a given temperature. This can be considered as the interruption of the sulfur vulcanization in $\mathrm{BR}_{-} \mathrm{SMF}_{1}$ at the initial stage of the reaction due to the formation of some bismalemide crosslinks via Alder-ene reaction. From the figures, it is clear that the maximum rate of reaction for all the compounds occurs at a temperature greater than zero. This implicates that all the compounds follow an autocatalytic type vulcanization reaction. Therefore, the autocatalytic model equation given in Equation (7) was employed to evaluate the kinetics of the cure reaction [28-30]:

$$
\frac{\mathrm{d} \alpha}{\mathrm{d} t}=k(T) \alpha^{\mathrm{m}}(1-\alpha)^{\mathrm{n}}
$$

where $\alpha$ is the degree of curing, $k$ is the rate constant at temperature, $T$ and $m$, and $n$ are orders of the reaction. The degree of curing was calculated from the MDR cure curves using the Equation (8):

$\alpha=\frac{S_{t}^{\prime}-S_{\text {min }}^{\prime}}{S_{\text {max }}^{\prime}-S_{\text {min }}^{\prime}}$ 

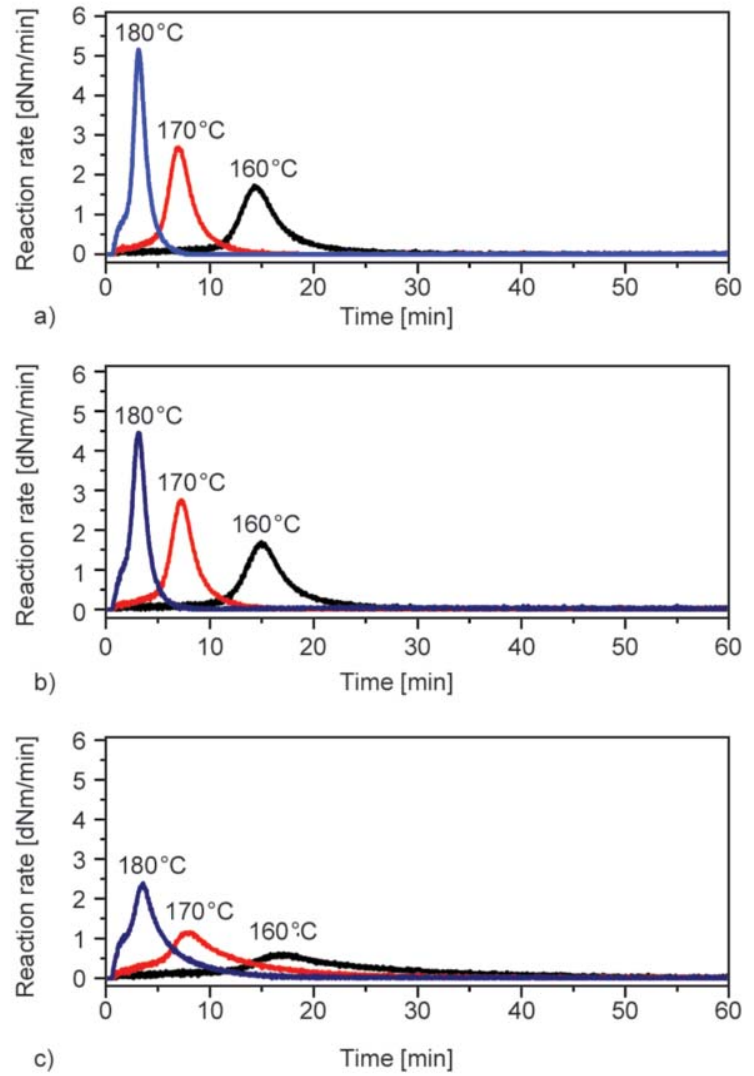

Figure 8. Cure rate curves of (a) BR-S, (b) BR-SPL 1 , and (c) BR-SMF 1 obtained from the MDR at different temperatures.

where $S_{\mathrm{t}}^{\prime}$ is the torque at time $t, S_{\min }^{\prime}$ is the minimum torque and $S_{\text {max }}^{\prime}$ is the maximum torque. The values of $k, m$ and $n$ were determined from the plot of the rate of cure conversion $(\mathrm{d} \alpha / \mathrm{d} t)$ versus degree of cure $(\alpha)$ using a non-linear regression fit with the help of a computer software Orgin Pro 8.5. A representative curve fitted between $\mathrm{d} \alpha / \mathrm{d} t v s . \alpha$ for all these compounds at $160^{\circ} \mathrm{C}$ is depicted in Figure 9. The values of the kinetic parameters $(k, m, n)$ obtained from the

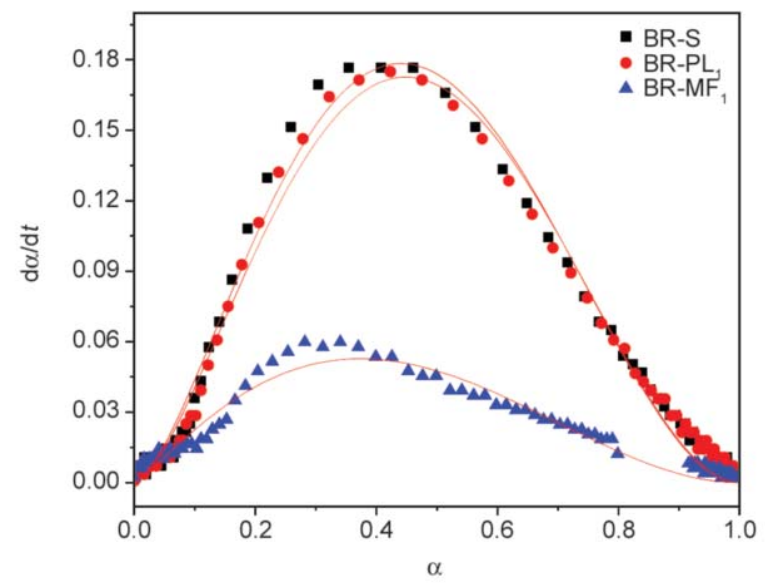

Figure 9. A representative plot between $\mathrm{d} \alpha / \mathrm{d} t$ versus $\alpha$ for BR-S, BR-SPL $L_{1}$ and BR-SMF 1 at $160^{\circ} \mathrm{C}$.
Table 4. Kinetic parameters of the curing reaction obtained from ODR.

\begin{tabular}{|l|c|c|c|c|c|}
\hline Compounds & $\begin{array}{c}\text { Temperature } \\
{\left[{ }^{\circ} \mathbf{C}\right]}\end{array}$ & $\boldsymbol{k}$ & $\boldsymbol{m}$ & $\boldsymbol{n}$ & $\begin{array}{c}\boldsymbol{E}_{\mathbf{a}} \\
{[\mathbf{k J} / \mathbf{m o l}]}\end{array}$ \\
\hline \multirow{3}{*}{ BR-S } & 160 & 2.12 & 1.59 & 2.02 & \multirow{3}{*}{44.9} \\
\cline { 2 - 5 } & 170 & 2.51 & 1.40 & 1.74 & \\
\cline { 2 - 5 } & 180 & 3.70 & 1.21 & 1.62 & \\
\hline \multirow{3}{*}{ BR-SPL $_{1}$} & 160 & 2.04 & 1.61 & 1.98 & \multirow{2}{*}{42.5} \\
\cline { 2 - 5 } & 170 & 2.66 & 1.47 & 1.75 & \\
\cline { 2 - 5 } & 180 & 3.44 & 1.02 & 1.50 & \\
\hline \multirow{3}{*}{ BR-SMF $_{1}$} & 160 & 0.44 & 1.19 & 2.00 & \multirow{2}{*}{53.0} \\
\cline { 2 - 5 } & 170 & 0.59 & 0.97 & 1.78 & \\
\cline { 2 - 5 } & 180 & 0.83 & 0.72 & 1.66 & \\
\hline
\end{tabular}

respective nonlinear regression fit curves at different vulcanization temperature from 160 to $180^{\circ} \mathrm{C}$ are represented in Table 4 . The rate constant $(k)$ for all the compounds increased with increasing the vulcanization temperature. However, at a given temperature, the rate constants for BR-S and BR-SPL $\mathrm{L}_{1}$ were comparable and that for $\mathrm{BR}_{-} \mathrm{SMF}_{1}$ was always lower

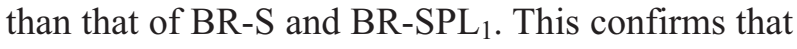
the vulcanization kinetics of polybutadiene rubber with accelerated sulfur will slowdown in the presence of MF. For further clarification, the activation energies of BR-S, BR-SPL ${ }_{1}$ and $\mathrm{BR}-\mathrm{SMF}_{1}$ were determined from their respective $\mathrm{k}$ values using the $\mathrm{Ar}$ rhenius Equation (9):

$\ln k(T)=\ln A-\frac{E_{\mathrm{a}}}{R T}$

where $A$ is the pre-exponential factor, $E_{\mathrm{a}}$ is the activation energy, $R$ is the universal gas constant, and $T$ is the temperature in Kelvin. Figure 10 represents the Arrhenius plot of $\ln k$ versus $1 / T$ for BR-S, BR-SPL 1 and $\mathrm{BR}-\mathrm{SMF}_{1}$. Their activation energies obtained from

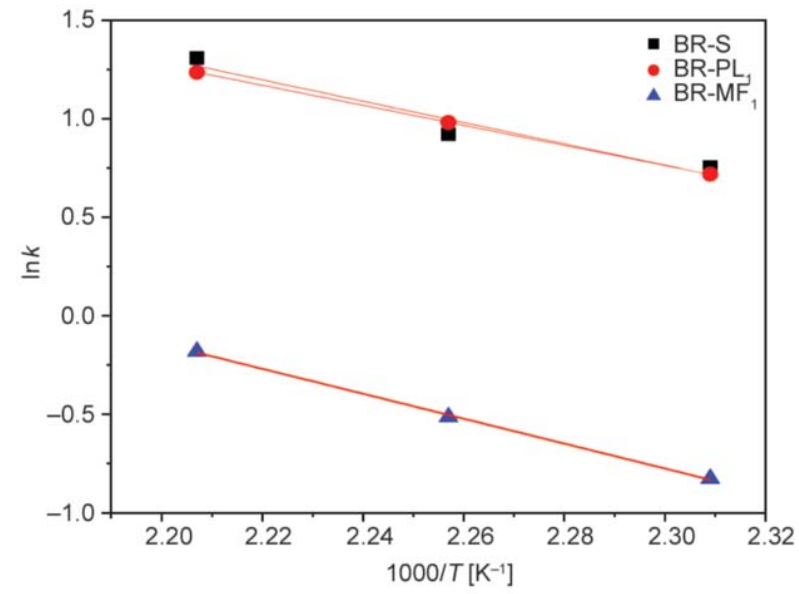

Figure 10. Arrhenius plot of lnk versus $1 / T$ for BR-S, BR-SPL $L_{1}$ and BR-SMF 1 . 
the respective slope values are also listed in Table 4. The activation energies of BR-S $(44.97 \mathrm{~kJ} / \mathrm{mol})$ and BR-SPL $1(42.4 \mathrm{~kJ} / \mathrm{mol})$ were almost comparable. However, $\mathrm{BR}-\mathrm{SMF}_{1}$ showed higher activation energy $(52.5 \mathrm{~kJ} / \mathrm{mol})$ compared to BR-S and BR-SPL ${ }_{1}$. The higher activation energy of $\mathrm{BR}-\mathrm{SMF}_{1}$ further substantiates the fact that the presence of MF will reduce the speed of accelerated sulfur vulcanization in polybutadiene rubber.

\subsection{Crosslink density and compression set}

\subsubsection{Influence of molding temperature on the} cross-link density

Depicted in Figure 11 are the chemical cross-link densities of BR-S, BR-SPL ${ }_{1}$, and BR-SMF ${ }_{1}$ molded at 160 and $180^{\circ} \mathrm{C}$ for the respective optimum cure times. Both the molded samples of BR-S and BR$\mathrm{SPL}_{1}$ at $160^{\circ} \mathrm{C}$ showed almost comparable crosslink densities. This was in good agreement with their respective $\Delta S^{\prime}$ (an indirect indication of the crosslink densities) values obtained from the rheometer studies. However, the cross-link density of BR$\mathrm{SMF}_{1}$ molded at $160^{\circ} \mathrm{C}$ was around $37 \%$ lower even if its $\Delta S^{\prime}$ was slightly higher compared to BR-S or BR-SPL $L_{1}$. This unexpected lowering of the crosslink density in BR-SMF 1 can be explained based on the nature of the vulcanization reaction and the type of cross-links formed in the vulcanized network. From Figures 3a, it can be seen that the vulcanization reaction in both BR-S and BR-SPL 1 proceeds the same pattern with the same speed till 30 minutes of curing. As a result, both these compounds may comprise all the three types of sulfur cross-links (mono-, di- and poly-sulfidic) in their vulcanized network at the same level. This may be the reason

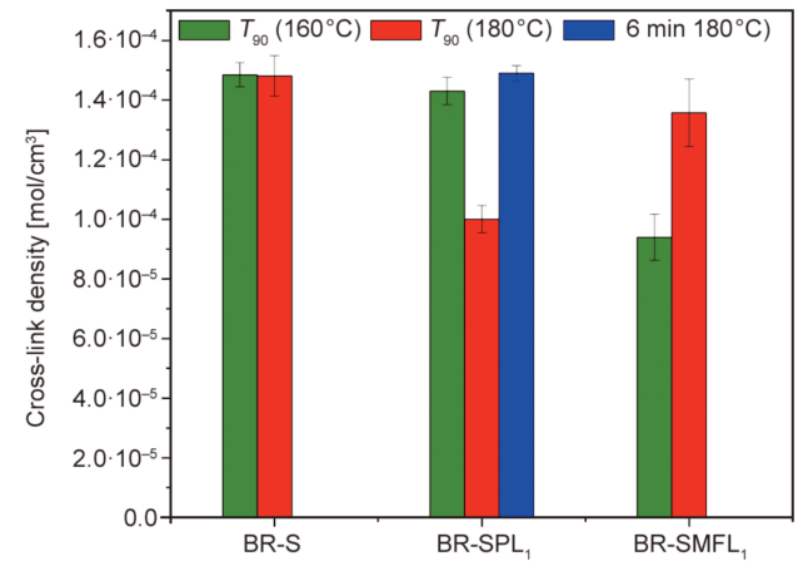

Figure 11. Chemical cross-link densities of BR-S, BR-SPL and BR-SMF 1 molded at 160 and $180^{\circ} \mathrm{C}$ for the respective optimum cure times. why the samples of BR-S and BR-SPL ${ }_{1}$ molded at $160^{\circ} \mathrm{C}$ as per their $T_{90}(20$ minutes $)$ exhibited the same cross-link densities. On the other hand, the speed of the vulcanization reaction in $\mathrm{BR}-\mathrm{SMF}_{1}$ at $160^{\circ} \mathrm{C}$ considerably reduced due to a parallel reaction (Alder-ene reaction) between $\mathrm{BR}$ and $\mathrm{MF}$ as depicted in Figure 6. From Figure 7a, 7b, it has been confirmed that the speed of the reaction between BR and MF is faster than the accelerated-sulfur vulcanization reaction in BR-S in the early stage. Therefore, it is reasonable to believe that the first crosslinks formed in the network of BR-SMF ${ }_{1}$ might be a carbon-carbon cross-link through the bismaleimide unit. Because of the bulky nature of the initially generated bismaleimide crosslinks, it may be hindered or slow down for the next bismaleimide unit being incorporated into the network as cross-links. Also, the bulky bismaleimide cross-link can slightly slow down the sulfur vulcanization reaction, which ultimately leads to reducing the number of sulfur-based cross-links in the vulcanized network. All these probable factors might be the reasons for the reduction in the overall chemical crosslink density in the samples of BR-SMF 1 molded at $160^{\circ} \mathrm{C}$ as per its $T_{90}$ value.

It was noticed that the samples of BR-S and BR$\mathrm{SPL}_{1}$ molded at $160^{\circ} \mathrm{C}$ as per their respective $T_{90}$ exhibited almost the same values of cross-link densities. However, the cross-link density of BR-SPL ${ }_{1}$ molded as per $T_{90}$ at $180^{\circ} \mathrm{C}$ was around $30 \%$ lower than the same molded as per the $T_{90}$ value at $160^{\circ} \mathrm{C}$. On the contrary, the crosslink density of BR-SMF 1 molded as per $T_{90}$ at $180^{\circ} \mathrm{C}$ was around $44 \%$ higher than the same molded as per the $T_{90}$ obtained at $160^{\circ} \mathrm{C}$. These discrepancies in the cross-link densities of BR-SPL $L_{1}$ and BR-SMF 1 can be explained based on the nature of the chemical reactions offered by the PL and MF during the vulcanization process at $180^{\circ} \mathrm{C}$. From the inset of Figure $3 \mathrm{~b}$, it is clear that the vulcanization curve of BR-SPL $L_{1}$ exhibits two distinct stages of cross-linking reaction at $180^{\circ} \mathrm{C}$. The first stage reaction can be considered as accelerated-sulfur vulcanization, which starts at $0.5 \mathrm{~min}$ utes and ends at 8 minutes. The second stage reaction seems to be very slow. It starts at around 12.5 minutes and continued till the end of the given 60 minutes curing time. Between 8 and 12.5 minutes, the cure curve exhibits a sign of reversion. Because of the reversion that happened between 8 and 12.5 minutes, BR-SPL 1 loses its initially formed network 
integration. This may be the reason why the compound of BR-SPL ${ }_{1}$ molded at $180^{\circ} \mathrm{C}$ for $T_{90}(23 \mathrm{~min}$ utes) exhibited a lower cross-link density. However, it is worth noting that the molded samples of BR$\mathrm{SPL}_{1}$ at $180^{\circ} \mathrm{C}$ for 6 minutes (before reversion) exhibited almost equal cross-link density compared to the same molded at $160^{\circ} \mathrm{C}$ as per $T_{90}$. Unlike BR$\mathrm{SPL}_{1}$, the Alder-ene reaction which was responsible for diminishing the speed of the vulcanization reaction in BR-SMF ${ }_{1}$ at $160^{\circ} \mathrm{C}$ became faster at $180^{\circ} \mathrm{C}$ owing to the lower activation energy. Consequently, more numbers of bismaleimide cross-links can get into the vulcanized network along with the sulfur based cross-links. This might be one of the plausible reasons for the enhanced cross-link density for the samples of BR-SMF 1 molded at $180^{\circ} \mathrm{C}$.

\subsubsection{Influence of molding time on the cross-link density}

To understand the network integrity and stability of the cross-links been formed in BRS, BRS-PL ${ }_{1}$, and BRS-MF ${ }_{1}$, the cross-link densities of these compounds were determined after molding them at $180^{\circ} \mathrm{C}$ under the different extent of time beyond their $T_{90}$. Represented in Figure 12 are the cross-link densities of BRS, BRS-PL 1 , and BRS-MF ${ }_{1}$ molded at $180^{\circ} \mathrm{C}$ as per $T_{90}, T_{90}+10$ minutes and $T_{90}+30$ minutes respectively. As expected, BR-S molded as per $T_{90}$ exhibited the highest cross-link density owing to its good network integrity. However, when the molding time elapsed 10 minutes beyond its $T_{90}$, the cross-link density was reduced to around $26 \%$, which further reduced to $46 \%$ as the molding time extended to 30 minutes beyond the $T_{90}$ value. Severe breakage of the polysulfidic cross-links and the subsequent

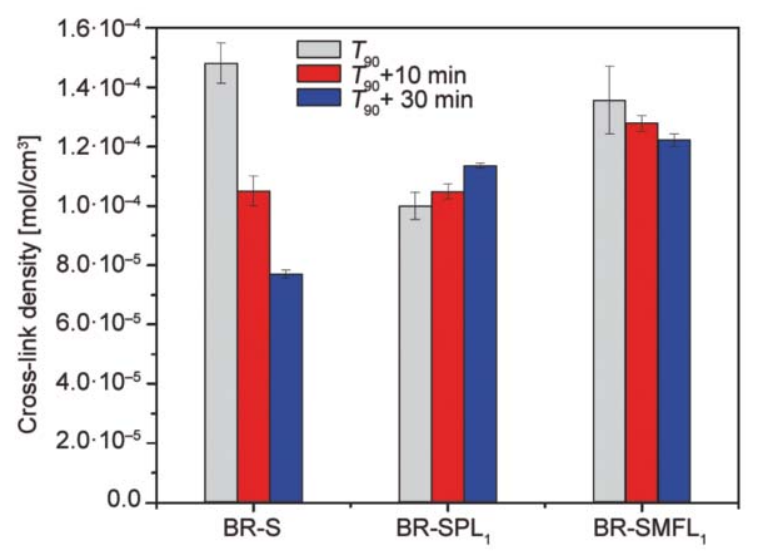

Figure 12. Cross-link densities of BRS, BRS-PL $\mathrm{P}_{1}$, and BRS$\mathrm{MF}_{1}$ molded at $180^{\circ} \mathrm{C}$ as per $T_{90}, T_{90}+10$ minutes and $T_{90}+30$ minutes. loss of the network integrity due to over curing was the primary reason for the drastic reduction in the cross-link densities of BR-S. In the case of BR-SPL ${ }_{1}$, the one molded as per its $T_{90}$ (23 minutes) showed the lowest cross-link density. However, about 5\% improvement in the cross-link density was observed when the molding time extended to 10 more minutes beyond its $T_{90}$. The improvement in cross-link density was further rose to $36 \%$ when it was molded for $T_{90}+30$ minutes. The formation of diene-Perkalink Diels-Alder adducts between the polymer chains beyond its $T_{90}$ is considered as one of the probable reasons for the enhanced crosslink density. Here it is worth noting that, though BR-SMF 1 exhibited a plateau type cure curve with no distinct sign of reversion beyond its $T_{90}$, the cross-link densities of its samples molded for $T_{90}+10$ minutes and $T_{90}+30$ minutes were also exhibited the same trend as seen in BR-S. However, when compared to BR-S, here, the reduction in the cross-link densities with the extended molding time beyond $T_{90}$ was marginal. For instance, only a $6 \%$ decrease in the crosslink density was experienced when the molding time for BR$\mathrm{SMF}_{1}$ extended to10 minutes beyond its $T_{90}$. The cross-link density was not reduced to more than $10 \%$ even if the curing time elapsed 30 minutes beyond its $T_{90}$. Unlike in the vulcanized network of BR-S or $\mathrm{BR}-\mathrm{SPL}_{1}$, the network formed in BR-SMF ${ }_{1}$ within $T_{90}$ comprises some carbon-carbon cross-links via Alder-ene reaction in addition to the sulfur-based cross-links. Since the Alder-ene reaction also consumes certain double bonds from the polymer, the amount of polysulfidic sulfur cross-links in BR$\mathrm{SMF}_{1}$ will be lower than those were present in BR-S or BR-SPL $L_{1}$. Because of the small amounts of the polysulpfidic cross-links together with the inherent thermal stability of the carbon-carbon cross-links, the network damage in BR-SMF 1 would not be as severe as observed in either BR-S or BR-SPL $L_{1}$ in the over-cure region. This may be one of the reasons why we have seen only a marginal reduction in the cross-link densities of the samples of BR-SMF 1 molded for $T_{90}+10 \mathrm{~min}$ and $T_{90}+30 \mathrm{~min}$ at $180^{\circ} \mathrm{C}$.

\subsubsection{Influence of molding (curing) time on the compression set properties}

The compression set is considered as an important property requirement for the rubber compounds used in the sealing applications. In general, lower the set value higher will be the sealing efficiency. Rubber 
compounds having a strong vulcanized network with high cross-link density usually exhibits a low compression set value [31]. Furthermore, the compression set will also depend on the strength of the chemical bonds in the vulcanized network. Generally, the bond energy of a $\mathrm{C}-\mathrm{C}$ cross-link ( $354 \mathrm{~kJ} / \mathrm{mol})$ is much higher than all the three types of sulfur based crosslinks such as $\mathrm{C}-\mathrm{S}_{\mathrm{X}}-\mathrm{C}(252 \mathrm{~J} / \mathrm{mol}), \mathrm{C}-\mathrm{S}_{2}-\mathrm{C}$ $(268 \mathrm{~kJ} / \mathrm{mol})$ and $\mathrm{C}-\mathrm{S}-\mathrm{C}(285 \mathrm{~kJ} / \mathrm{mol})$ [2]. Therefore, it is quite obvious that if any bismaleimide cross-links are generated in the vulcanized network, the overall thermal stability of the network will be higher. Represented in Figure 13 are the set value of BR-S, BR-SPL $L_{1}$ and BR-SMF ${ }_{1}$ molded at $180^{\circ} \mathrm{C}$ for different molding times. All these compounds showed a gradually decreasing trend in the set values as the molding time increased. If we evaluate the set properties in terms of cross-link density, this trend was quite unexpected, particularly in BR-S. In terms of cross-link density, the one molded at $180^{\circ} \mathrm{C}$ for 30 minutes should have been exhibited the highest set value than the one molded at 10 minutes under the given conditions. But, the reverse was found true here. For instance, BR-S molded at 10 minutes shows a set value of $46.62 \%$, which has been reduced to $29.91 \%$ as the molding time was extended for 30 minutes. One of the most probable reasons for the low set value of the 30 minutes molded compounds might be due to the breakage and transformation of the less thermally stable poly-sulfidic crosslinks in its vulcanized network to a more thermally stable mono and di-sulfidic cross-links. Here it is important to note

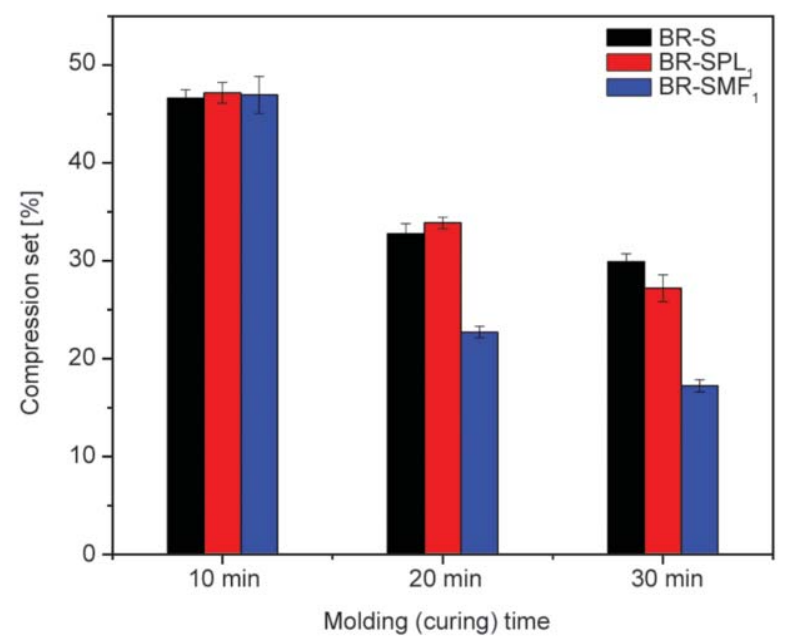

Figure 13. Compression set values of BR-S, BR-SPL ${ }_{1}$ and BR-SMF 1 molded at $180^{\circ} \mathrm{C}$ for different molding times. that the set values of all the compounds molded up to 10 minutes and the compounds BR-S and BR-SPL molded up to 20 minutes were almost comparable. This implies that the sulfur-based cross-links generated in the vulcanized network of these compounds within 20 minutes of molding (curing) are largely controlling their set values. On the other hand, BR$\mathrm{SMF}_{1}$ molded for 20 minutes exhibits a set value of around $22.7 \%$. At the same time, the set values for the 20 minute molded BR-S and BR-SPL ${ }_{1}$ were 32.78 and $33.87 \%$ respectively. When the molding time extended up to 30 minutes, the set value of BR$\mathrm{SMF}_{1}$ further reduced to $17.24 \%$. This low set value of BR-SMF 1 might be due to the formation of considerable amounts of thermally stable carbon-carbon cross-links in the vulcanized network via Alder-ene reaction between $\mathrm{BR}$ and $\mathrm{MF}$.

\subsection{Thermogravimetric Analysis}

From the compression set studies, it has been observed that when the bismaleimide units through Perkalink or MF get incorporated in the vulcanized network as cross-links, the thermal stability of the resultant vulcanizate become significantly improved. To support this observation, the thermogravimetric analysis of the vulcanized samples of BR-S, BR$\mathrm{SPL}_{1}$, and BR-SMF 1 were performed under a nitrogen atmosphere from room temperature to $600^{\circ} \mathrm{C}$. The BR-S taken for this study was molded at $180^{\circ} \mathrm{C}$ as per $T_{90}$. However, the samples of BR-SPL 1 and $\mathrm{BR}-\mathrm{SMF}_{1}$ were used after molding them at $180^{\circ} \mathrm{C}$ for $T_{90}+30$ minutes to ensure the presence of the

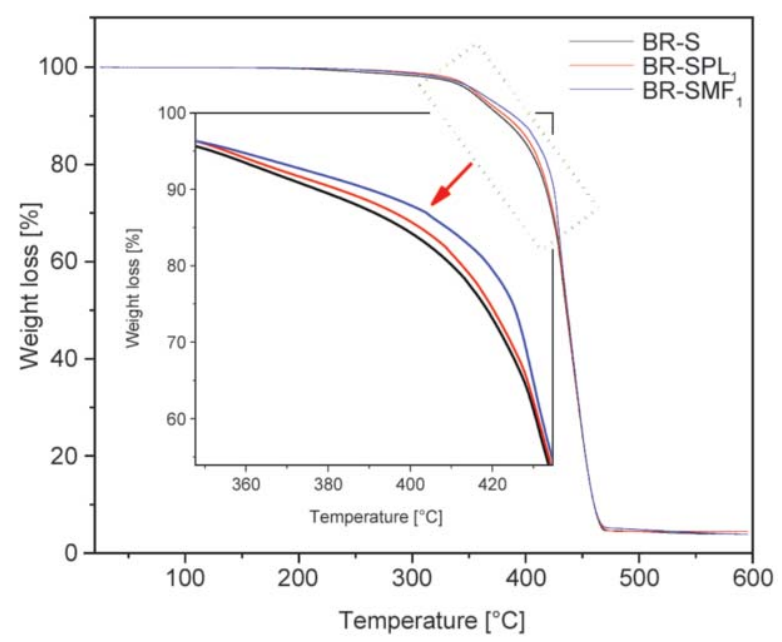

Figure 14. TGA curves of the cured samples BR-S, BR$\mathrm{SPL}_{1}$, and BR-SMF 1 . BR-S was cured as per $T_{90}$ and $\mathrm{BR}-\mathrm{SPL}_{1}$ and $\mathrm{BR}-\mathrm{SMF}_{1}$ were cured as per $T_{90}+30$ minutes at $180^{\circ} \mathrm{C}$ ). 
maleimide cross-links in the vulcanized network. Represented in Figure 14 are the weight loss vs. temperature curves of BR-S, BR-SPL ${ }_{1}$, and BR-SMF 1 . It is clear from the figure that the onset temperature (the temperature at $5 \%$ weight loss, $T_{5 \%}$ ) for the thermal degradation of BR-S was slightly improved by $3.5^{\circ} \mathrm{C}$ when it was vulcanized in the presence of $1 \mathrm{phr}$ Perkalink 900 . The $T_{5 \%}$ of BR-S further moved to the higher temperature side by $6.3^{\circ} \mathrm{C}$ when it was vulcanized with $1 \mathrm{phr}$ MF. This thermal analysis data substantiate the fact that the bismaleimide crosslinks in the vulcanized network improve the overall thermal stability of the system.

\subsection{Influence of MF content on the vulcanization behavior and the vulcanizate properties}

Based on the above studies, it has been confirmed that MF is a promising chemical to enhance the reversion resistance in an industrially acceptable manner at a higher vulcanization temperature. Moreover, the crosslink density and set properties of the vulcanizate contains MF were better than those with PL900. Therefore, a detailed investigation regarding how the content of MF affects the vulcanization behavior and the vulcanizate properties like cross-linking density, compression set, and shore hardness were also evaluated. Represented in Figure 15 are the MDR cure curves of BR-S with different content of MF at $180^{\circ} \mathrm{C}$ for $60 \mathrm{~min}$. Their corresponding cure characteristics are listed in Table 5 . The addition of MF does not significantly alter the scorch time $\left(T_{\mathrm{S} 2}\right)$ of BR-S. However, its $T_{90}$ and the $S_{\text {max }}^{\prime}$ were gradually increased as the content of MF increased. The increase of $S_{\text {max }}^{\prime}$ or $\Delta S_{\text {max }}^{\prime}$ with the content of MF is an indication of the enhanced crosslink density. As the content of MF increased, more bismaleimide crosslinks may be produced into the vulcanized network. Because of the bulky nature of the initially formed bismalimide crosslinks, it may slow down the formation of the most expected sulfur crosslinks and also may slow down the formation of

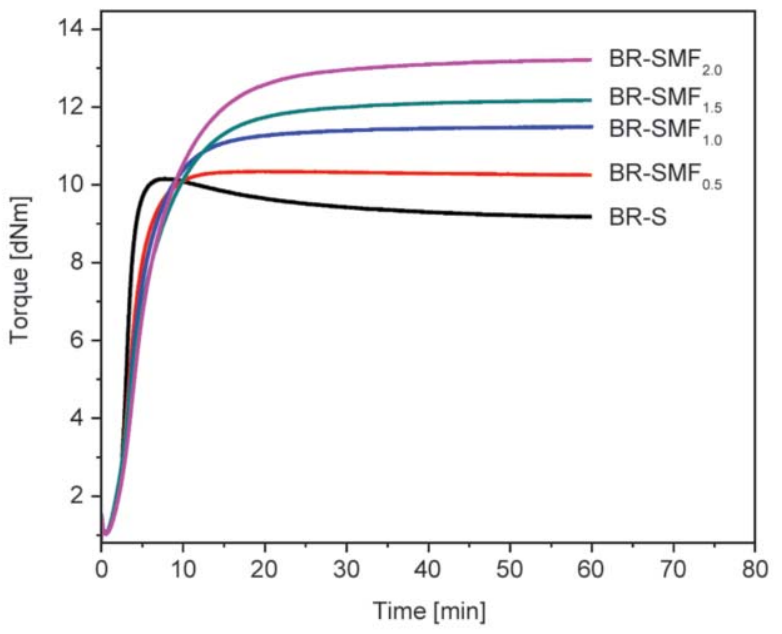

Figure 15. Cure curves of BR-S with different content of $\mathrm{MF}$ at $180^{\circ} \mathrm{C}$ for $60 \mathrm{~min}$.

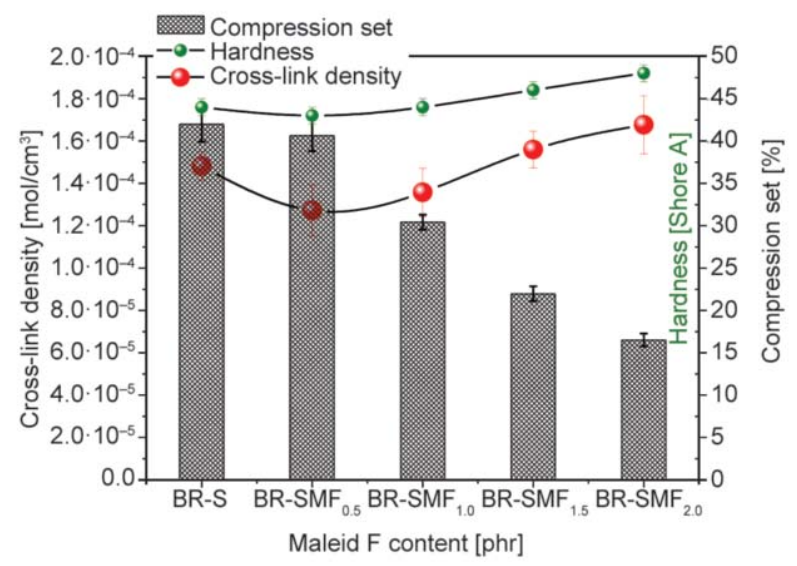

Figure 16. Crosslink density, compression set, and shore-A hardness values of BR-S with different contents of MF. [All the samples were molded as per $T_{90}$ for measuring crosslink density. However, a molding time of $T_{90}+5$ minutes at $180^{\circ} \mathrm{C}$ was given for making the samples for measuring both the compression set as well as hardness.]

further bismaleimide cross-links. As a result, BR-S exhibits a slow curing behavior beyond $0.5 \mathrm{phr}$ addition of MF, consequently takes a longer time to reach the optimum cure state. Therefore, the recommended concentration of MF for a balanced $T_{\mathrm{S} 2}$ and $T_{90}$ with excellent anti-reversion property would be in the range of 0.5 to $1.0 \mathrm{phr}$. Represented in Figure 16 are the crosslink density, compression set, and

Table 5. Cure characteristics of BR-S with different contents of $\mathrm{MF}$ at $180^{\circ} \mathrm{C}$.

\begin{tabular}{|c|c|c|c|c|c|c|}
\hline MF content & $S_{\text {min }}^{\prime}$ & $S_{\text {max }}^{\prime}$ & $\Delta S^{\prime}$ & $\begin{array}{c}T_{\mathrm{S} 2} \\
{[\mathrm{~min}]}\end{array}$ & $\begin{array}{c}T_{90} \\
{[\mathrm{~min}]}\end{array}$ & $\begin{array}{c}\text { Cure rate index } \\
{\left[\mathrm{min}^{-1}\right]}\end{array}$ \\
\hline BR-SMF $_{0.5}$ & 1.0 & 10.5 & 9.5 & 2.6 & 7.0 & 22.7 \\
\hline BR-SMF $_{1.0}$ & 1.1 & 11.5 & 10.4 & 2.6 & 10.3 & 13.0 \\
\hline BR-SMF $_{1.5}$ & 1.0 & 12.2 & 11.2 & 2.5 & 13.4 & 9.2 \\
\hline $\mathrm{BR} \mathrm{SMF}_{2.0}$ & 1.0 & 13.1 & 12.1 & 2.3 & 14.2 & 8.4 \\
\hline
\end{tabular}


shore-A hardness values of BR-S with different contents of MF. Here, the samples used for measuring the cross-link densities were molded as per the respective $T_{90}$ values at $180^{\circ} \mathrm{C}$. However, a molding time of $T_{90}+5$ minutes was given for making the samples for measuring both the compression set as well as hardness. The changes in the cross-link densities of BR-S with the addition of MF was not linear. It is clear from the figure that the cross-link density of BR-S decreased by $14.1 \%$ with the addition of $0.5 \mathrm{phr}$ MF. The intensity of reducing the crosslink density was quenched to $8.3 \%$ with the addition of $1 \mathrm{phr}$ MF. Later, the cross-link density was slightly improved to $5.3 \%$ with $1.5 \mathrm{phr}$ addition of MF and further improved to $13.2 \%$ as the MF content rose to 2 phr. However, both the hardness and the compression set values of BR-S have exhibited a linear change as the MF content increased. Here, the hardness gradually increased from 44 to 48 Shore A with the content of MF increased from 0 to $2 \mathrm{phr}$ MF and the compression set values were gradually decreased from 42 to $16.3 \%$ as the MF content rose from 0 to $2 \mathrm{phr}$.

\section{Conclusions}

From this study, it has been identified that both the PL 900 and MF can show anti-reversion activity during the accelerated sulfur vulcanization of polybutadiene rubber. However, the performance of Perkalink in terms of both its curing and anti-reversion ability was at its best only at $160^{\circ} \mathrm{C}$. As the vulcanization temperature raised to well above $160^{\circ} \mathrm{C}$, the PL exhibits its anti-reversion ability only after considerable damage has happened in the vulcanized network. Therefore, PL cannot be recommended as a promising anti-reversion agent for the high-temperature vulcanization of diene-rubbers with accelerated sulfur. On the other hand, MF can directly react with the polybutadiene chains during the initial stage of the vulcanization reaction and produces bismaleimide crosslinks via Alder-ene reaction along with the sulfur crosslinks. Owing to the high thermal stability of the bismaleimide crosslinks, the compounds contain MF do not exhibit any sign of reversion even at elevated temperatures. Moreover, the crosslink density of the compound with $1 \mathrm{phr}$ MF vulcanized for $T_{90}+30 \mathrm{~min}$ at $180^{\circ} \mathrm{C}$ was $58.5 \%$ higher than those without any MF and about $7.5 \%$ higher than those with $1 \mathrm{phr}$ PL. Similarly, the compound with $1 \mathrm{phr}$ MF vulcanized for 30 minutes at $180^{\circ} \mathrm{C}$ exhibits the lowest compression set of $17.24 \%$ at $100^{\circ} \mathrm{C}$ for $22 \mathrm{hrs}$.
At the same time, it was around $27.24 \%$ for the compound with $1 \mathrm{phr}$ PL and around $29.9 \%$ without any bismaleimides. Therefore, MF can be recommended as a trustworthy chemical to enhance the reversion resistance for the high-temperature vulcanization of diene-rubbers with accelerated sulfur and also to improve the vulcanizate properties such as cross-linking density and compression set.

\section{Acknowledgements}

This article was written with the support of the project Centre of Polymer Systems-Strengthening Research Capacity reg. number: CZ.1.05/2.1.00/19.0409, NPU I reg. number: LO1504 as well as reg. number: CZ.02.2.69/0.0/0.0/16_027/0008464

\section{References}

[1] Akiba M., Hashim A. S.: Vulcanization and crosslinking in elastomers. Progress in Polymer Science, 22, 475-521 (1997). https://doi.org/10.1016/S0079-6700(96)00015-9

[2] Kruželák J., Sýkora R., Hudec I.: Sulphur and peroxide vulcanisation of rubber compounds - Overview. Chemical Papers, 70, 1533-1555 (2016). https://doi.org/10.1515/chempap-2016-0093

[3] Rajesh Babu R., Shibulal G. S., Chandra A. K., Naskar $\mathrm{K}$.: Compounding and vulcanization. in 'Advances in elastomers I. Advanced structured materials' (eds.: Visakh P., Thomas S., Chandra A., Mathew A.) Springer, Berlin, Heidelberg, Vol. 11, 83-138 (2013).

https://doi.org/10.1007/978-3-642-20925-3_4

[4] Dijkhuis K. A. J., Noordermeer J. W. M., Dierkes W. K.: The relationship between crosslink system, network structure and material properties of carbon black reinforced EPDM. European Polymer Journal, 45, 33023312 (2009).

https://doi.org/10.1016/j.eurpolymj.2009.06.029

[5] Loo C. T.: High temperature vulcanization of elastomers: 2. Network structures in conventional sulphenamide-sulphur natural rubber vulcanizates. Polymer, 15, 357-365 (1974). https://doi.org/10.1016/0032-3861(74)90177-3

[6] Loo C. T.: High temperature vulcanization of elastomers: 3. Network structure of efficiently vulcanized natural rubber mixes. Polymer, 15, 729-737 (1974). https://doi.org/10.1016/0032-3861(74)90025-1

[7] Bhowmick A. K., Mukhopadhyay R., De S. K.: High temperature vulcanization of elastomers. Rubber Chemistry and Technology, 52, 725-734 (1979). https://doi.org/10.5254/1.3535236

[8] Datta R. N.: A review on heat and reversion resistance compounding. Progress in Rubber, Plastics and Recycling Technology, 19, 143-170 (2003). https://doi.org/10.1177/147776060301900302 
[9] Blok E. J., Kralevich M. L., Varner J. E.: Preliminary studies on new anti-reversion agents for the sulfur vulcanization of diene rubbers. Rubber Chemistry and Technology, 73, 114-120 (2000).

https://doi.org/10.5254/1.3547573

[10] Kenneth B.: Enhancing the reversion resistance of natural rubber compounds. Rubber World, 249, 27-32 (2013).

[11] Schotman A. H. M., van Haeren P. J. C., Weber A. J. M., van Wijk F. G. H., Hofstraat J. W., Talma A. G., Steenbergen A., Datta R. N.: Studies on a new antireversion agent for sulfur vulcanization of diene rubbers. Rubber Chemistry and Technology, 69, 727-741 (1996). https://doi.org/10.5254/1.3538397

[12] Datta R. N., Schotman A. H. M., Weber A. J. M., van Wijk F. G. H., van Haeren P. J. C., Hofstraat J. W., Talma A. G., Bovenkamp-Bouwman A. G. V. D.: Biscitraconimides as anti-reversion agents for diene rubbers: Spectroscopic studies on citraconimide-squalene adducts. Rubber Chemistry and Technology, 70, 129 145 (1997).

https://doi.org/10.5254/1.3538413

[13] Datta R. N., Talma A. G., Schotman A. H. M.: Comparative studies on the crosslinking reaction of bismaleimides and bis-citraconimides in squalene and natural rubber. Rubber Chemistry and Technology, 71, 1073-1086 (1998).

https://doi.org/10.5254/1.3538511

[14] Kumar N. R., Chandra A. K., Mukhopadhyay R.: Effect of 1,3-bis(citraconimidomethyl) benzene on the aerobic and anaerobic ageing of diene rubber vulcanizates. Journal of Materials Science, 32, 3717-3725 (1997). https://doi.org/10.1023/A:1018655102644

[15] Shibulal G. S., Jang J., Yu H. C., Huh Y. I., Nah C.: Cure characteristics and physico-mechanical properties of a conventional sulphur-cured natural rubber with a novel anti-reversion agent. Journal of Polymer Research, 23, 237-248 (2016).

https://doi.org/10.1007/s10965-016-1128-9

[16] Flory P. J., Rehner J.: Statistical mechanics of crosslinked polymer networks I. Rubberlike elasticity. Journal of Chemical Physics, 11, 512-520 (1943).

https://doi.org/10.1063/1.1723791

[17] Flory P. J., Rehner J.: Statistical mechanics of crosslinked polymer networks II. Swelling. Journal of Chemical Physics, 11, 521-526 (1943).

https://doi.org/10.1063/1.1723792

[18] Flory P. J.: Statistical mechanics of swelling of network structures. Journal of Chemical Physics, 18, 108-111 (1950). https://doi.org/10.1063/1.1747424

[19] Small P.: Some factors affecting the solubility of polymers. Journal of Applied Chemistry, 3, 71-80 (1953). https://doi.org/10.1002/jctb.5010030205

[20] Scott R. L., Magat M.: Thermodynamics of high-polymer solutions. III. Swelling of cross-linked rubber. Journal of Polymer science, 4, 555-571 (1949).

https://doi.org/10.1002/pol.1949.120040502
[21] Marzocca A. J., Rodríguez Garraza A. L., Mansilla M. A.: Evaluation of the polymer-solvent interaction parameter $\chi$ for the system cured polybutadiene rubber and toluene. Polymer Testing, 29, 119-126 (2010). https://doi.org/10.1016/j.polymertesting.2009.09.013

[22] Jackson K. D. O., Loadman M. J. R., Jones C. H., Ellis G.: Fourier transform Raman spectroscopy of elastomers: An overview. Spectrochimica Acta Part A: Molecular Spectroscopy, 46, 217-226 (1990). https://doi.org/10.1016/0584-8539(90)80091-C

[23] Datta R. N., Hofstraat J. W., Geurts F. A. J., Talma A. G.: Fourier transform Raman spectroscopy for characterization of natural rubber reversion and of antireversion agents. Rubber Chemistry and Technology, 72, 829-843 (1999).

https://doi.org/10.5254/1.3538835

[24] Coran A. Y.: Chemistry of the vulcanization and protection of elastomers: A review of the achievements. Journal of Applied Polymer Science, 87, 24-30 (2003). https://doi.org/10.1002/app.11659

[25] Hoffmann H. M. R.: The ene reaction. Angewandte Chemie, International Edition, 8, 556-577 (1969). https://doi.org/10.1002/anie.196905561

[26] Sebastian A. C., Pamela C. C., Maria F. P., Lorena M. M.: Theoretical characterization of the mechanism of Alder-ene reactions. Trends in Physical Chemistry, 16, 9-16 (2016).

[27] Sathi G. S., Jeon J., Won J., Nah C.: Enhancing the efficiency of zinc oxide vulcanization in brominated poly (isobutylene-co-isoprene) rubber using structurally different bismaleimides. Journal of Polymer Research, 25, 108/1-108/14 (2018). https://doi.org/10.1007/s10965-018-1512-8

[28] Kader M. A., Nah C.: Influence of clay on the vulcanization kinetics of fluoroelastomer nanocomposites. Polymer, 45, 2237-2247 (2004).

https://doi.org/10.1016/j.polymer.2004.01.052

[29] Shibulal G. S., Jang J. Y., Jeong K-U., Nah C.: Synergistic effect of 4,4'-bis(maleimido) diphenylmethane and zinc oxide on the vulcanization behavior and thermo-mechanical properties of chlorinated isobutyleneisoprene rubber. Polymers for Advanced Technologies, 28, 742-753 (2017). https://doi.org/10.1002/pat.3976

[30] Gopisathi S., Park C., Huh Y. I., Jeon J., Yun C. H., Won J., Jeong K-U., Nah C.: Enhancing the reversion resistance, crosslinking density and thermo-mechanical properties of accelerated sulfur cured chlorobutyl rubber using 4,4'-bis (maleimido) diphenyl methane. Rubber Chemistry and Technology, 92, 110-128 (2019). https://doi.org/10.5254/rct.18.82605

[31] Movahed S. O., Ansarifar A., Mirzaie F.: Effect of various efficient vulcanization cure systems on the compression set of a nitrile rubber filled with different fillers. Journal of Applied Polymer Science, 132, 41512/1-41512/10 (2015). https://doi.org/10.1002/app.41512 